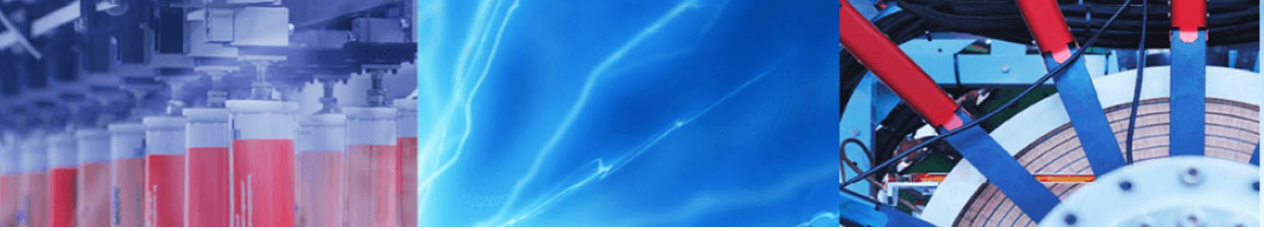

Research Article

\title{
Design, fabrication and testing of a magnetorheologic fluid braking system for machine tool application
}

\author{
Rakesh Jinaga ${ }^{1}$. Jagadeesha Thimmaiah ${ }^{1} \cdot$ Kolekar Shreedhar $^{2} \cdot$ Choi Seung-Bok $^{3}$
}

(c) Springer Nature Switzerland AG 2019

\begin{abstract}
This technical article introduces a governable brake system that can be relevant for different machines, developed using magnetorheologic (MR) fluids. As an initial step, new MR fluids are developed considering different compositions of various constituents pursued by the formulation of a numerical model considering various elements such as magnetic field strength, magnetic particle size and MR fluid yield strength. Using a commercial software, COMSOL, a magnetically energized circuit is examined to obtain the details regarding the number of turns, current supply and strength of the magnetic field at predefined points, and a simulation study is carried out. Successively, the developed and optimized MR fluid is introduced between the gap of the fixed plate and rotating disk under the influence of the magnetic field over the fluid territory. A full-fledged test rig setup for the MR brake system is established, and an experimental study is carried out focusing on the shaft speed and braking torque developed during the braking process. The results are also plotted for various current input values. The current input value ranges from 0 to $2 \mathrm{amp}$, and the respective torque value is obtained. Likewise, the performance of the torque by the proposed MR brake system used simulated results in a derived theoretical model, and a comparative study is carried out with the experimented results.
\end{abstract}

Keywords Magnetorheologic fluid $\cdot$ Torque transmission $\cdot$ MR brake $\cdot$ Magnetic analysis $\cdot$ Sedimentation rate

\section{List of symbols}

$H \quad$ Magnetic fielddirection

$E_{12} \quad$ Dipole interaction between $\mathrm{m}_{1}$ and $\mathrm{m}_{2}$

$\mu_{1} \quad$ Relative permeability

$m$ Dipole moment for identical strength

$U$ Energy density of particle

$\emptyset \quad$ Particle volume fraction

$d$ Diameter of particle

$\varepsilon \quad$ Shear strain, $x / r$

$\sigma \quad$ Shear stress

Jp Particle polarization

Js Saturation particle polarization

$\sigma_{y} \quad$ Maximum shear stress

$\emptyset_{p} \quad$ Flux through the saturated and unsaturated particle region

$\mathrm{Rm}$ Matrix reluctance

Rp Particle reluctance
$B \quad$ Flux density

A Area

$T$ Developed torque

$r \quad$ Disc radius

$N \quad$ Disc speed

\section{Introduction}

New technical advancements in the engineering domain and desire for a luxurious life have led to a wide range of opportunities to manipulate existing systems to optimize advanced operational systems. The automotive domain is one with upgrading of conventional braking systems with a magnetorheologically operational braking system. This braking system offers reliability with great efficiency as the magnetorheologic fluid is the operational fluid in

KolekarShreedhar, shreedharkolekar@gmail.com $\mid{ }^{1}$ National Institute of Technology, Calicut 673601 , India. ${ }^{2}$ Satara College of Engineering and Management Limb, Satara 415 015, India. ${ }^{3}$ Inha University, Incheon 22212, South Korea.

SN Applied Sciences (2019) 1:328 | https://doi.org/10.1007/s42452-019-0236-7 
the braking system. Magnetorheologic (MR) fluids are a class of smart fluids that undergo an apparent viscosity modification under the influence of an applied magnetic field. MR fluid is composed of three substrates, the carrier fluid, magnetic particles and additives. The carrier fluid comprises most of the fluid and is commonly known as the base fluid. A base fluid should possess characteristics similar to those of brake oil such as a high viscosity index, low cloud and pour points, high flash points, etc. The magnetic particles contribute to the second major part of the MR fluid, also known as the dispersed phase. The basic property of the dispersed phase is its magnetic nature, which enables and promotes the change in the apparent viscosity of the fluid under the magnetic field. The size of the magnetic particles dispersed in the fluid is on the micron scale with the shape being elliptical or spherical. Under normal circumstances, i.e., nonmagnetic conditions, the particles are randomly dispersed in the base fluid. Additives are the last and least but very important constituents of the fluid. The wide density difference among the base fluid and dispersed particles, which results in sedimentation of particles, is nullified to a great extent by the additives. Additives can be further classified as surfactants and stabilizers. The rheologic behavior of MR fluid is the same as that of the carrier fluid when no external magnetic field is present. When exposed to a magnetic field, the iron particles acquire a dipole-dipole moment and align along the applied magnetic field to form linear chains parallel to the field. The MR fluid is one of the most active "smart materials" of the current phase. Most of the developments in the application of the MRFs are focused on structural vibration control and flow power systems. Stanway et al. [1] and Wang and Meng [2] made a survey study on the state of the MRFs and their application in several mechanical engineering systems. Many papers deal with the application of MR fluids for controllable dampers [3-5], seismic response control of frame structures [6] and vibration control of large structures [7]. The rapid, reversible and dramatic changes in their rheologic properties allow the control of flow power systems $[8,9]$.

Selection criteria for MR fluid components play a critical role as the change in one or more components or in their properties influences the MR effect. The commonly used carrier fluids are silicone, mineral and synthetic oils. Mineral oils are not good for the environment, and synthetic oils are expensive. Silicone oil is preferred because of good heat-transfer characteristics, high flash points and temperature stability, and there is little change in physical properties over a wide temperature range with a relatively flat viscosity temperature and serviceability ranging from -40 to $204^{\circ} \mathrm{C}$ [10-14]. Magnetic particles used are of the micrometer size, and the particle size distribution ranges from 1 to $10 \mu \mathrm{m}$. The stability of the fluid increases with decreased size of the magnetic particles. Also, the stabilizers are added to the fluid to ensure particle suspension in the carrier fluid. The surfactants are adsorbed on the surface of the magnetic particles to enhance the stability of the fluid, and also polarization is induced in the suspended particles upon the application of a magnetic field $[10,15]$.

Many MR fluid applications operate under different modes such as the valve, shear and squeeze modes. The application of MR fluid in the braking system is a flourishing research field with various developments. The MR brake (MRB) is a device to transmit torque by the shear stress of MR fluid. A few experimental studies have been carried out on broadly useful MR brakes. Li et al. [18] were one of the initial designers of a working MR braking system. Park [16, 19] and Karakoc [17] investigated MR brakes for car applications. Hiraniet al. [13] presented an experimental study of a designed and fabricated high-speed MR brake. They also researched the impact of speed and the MR gap on the resulting torque of the MR brake. Nguyen et al. [20-22] added to the examination of MR brakes with a design and advanced consideration. They built an enhanced MR brake for motorbike application [22]. Assadsangabi [23] and Younis [24] utilized the SEMURE and GA algorithms to optimize the design parameters of an MR brake. Marannano [25] introduced magneto-static finite element analysis to evaluate the resulting torque of an MR brake visualized for an average-size automobile application. Sarkar [12] and Hirani [26] investigated the working of MR brakes in squeeze mode to enhance the output torque of the MR brake, also attempting a parabolic profiled MR brake. Patil [27] published the thermal analysis for an MR brake functioning in a car. Patil et al. [28] examined the dependability factor of an MR braking system, while Abdullah [29] introduced an MR brake employing a PID controller at different speeds and loads.

The Poznic and Casniji [30] studies analyzed a cylindrical MR brake. In this MR rotary disc brake, its braking torque changes quickly in response to an external magnetic field strength. Also, a theoretical study considered a design alternative for the usual simple MR fluid brakes. Edward et al. [19] studied the development of a new electromechanical brake system using MR fluid. The proposed brake system consists of rotating discs immersed in an MR fluid and enclosed in an electromagnet, where the yield stress of the fluid varies as a function of the magnetic field applied by the electromagnet. Sukwani and Hirani [13] described the design procedure for an MR brake and discussed the effect of the MR gap on its braking torque. Two brakes, the first with an MR gap of $1 \mathrm{~mm}$ and the second with an MR gap of $2 \mathrm{~mm}$, were designed and fabricated. Shrikant et al. [31] introduced a magnetorheologic brake model used for stopping a two-wheeler vehicle under consideration. First, the braking torque required to stop the 
vehicle was calculated analytically. Then, the appropriate design parameters were selected, and a model was developed using MATLAB software to achieve the same braking torque. Kavlicoglu et al. [32] focused on the design and characterization of a radial double-plate magnetorheologic fluid (MRF) clutch. The clutch's torque output can be controlled by adjusting the applied magnetic field. Electromagnetic finite element analysis (FEA) is performed to design and optimize the clutch.

Tan et al. [33] developed a mathematical model of an ER brake, and the modeled results were compared with the experimental output velocity responses of the brake. After the model validation was completed, the ER brake was subjected to various loads, electric fields, fluid temperatures and volume fractions. By observing the effect of each input variable, the trend behavior of the ER braking velocity response was investigated in an attempt to identify suitable parameters that can halt a robot arm at the fastest time durations. Benetti and Dragoni [34] studied the nonlinear magnetic behavior of a $100-\mathrm{Nm}$, multidisc MR rotary brake or clutch using COMSOL multiphasic software. Along with the analysis results, the merits and limitations of using the software for future simulations of the thermal and the mechanical responses of the device were found. Poznic et al. [35] introduced a review of all MR brake types. Based on the overall braking torque, an analytical comparison of all MR brake types and other relevant parameters was made. As a test rig utilizing a selected brake type filled with MR fluid, the Basonetic 5030 was manufactured and then tested. As evident from the literature survey, most of the previous work on MR brakes has focused on field-dependent braking performance. There is little research on the performance differences using different MR fluids.

In this work, three different MR fluids featuring three different iron particle weights and an amount of additive are synthesized and applied to an MR brake (MRB in short) to identify the dependence of the braking performance on the material properties of the MR fluid. Unlike the conventional hydraulic brake (CHB), which uses friction between the pads and surface, here the braking torque generation is different. MR fluid that can instantaneously change from the liquid to semisolid state by application of a magnetic field is used. This shear stress of the semi-solid generates the required braking torque. The MRB consists of rotating disks immersed in MR fluid and an enclosed electromagnet $[12,36]$. When current is supplied to the electromagnet coil, the MR fluid changes its state from liquid to semi-solid; also, the yield stress varies as a function of the magnetic field applied by the electromagnet. The required braking torque is achieved by controllable yield stress producing shear friction on the rotating disk. The MRB actuator is only controlled electronically, so it has the potential to reduce the response time of the system. It can be easily integrated with the existing and advanced technologies, such as an anti-lock braking system $(A B S)$, electronic parking brake (EPB) and vehicle stability control (VSC), as effective machines.

\section{Mathematical modeling of sheer stress}

The change of MR fluid from a Newtonian fluid to semi-solid is mathematically modeled using the basic magnetic induction equations. In most models of MR fluid, behavior is based on magnetic dipole-dipole interactions between adjacent particles in a particle chain structure. These inter-particle interactions are then averaged over the entire sample to yield a model of the bulk magnetorheologic effect. Figure 1 shows a dipole model of the particle energy interaction between two magnetic dipoles induced in the MR fluid by the application of a magnetic field.

Two particles are within a chain. Adjacent chains are a distance apart, and $h=r_{0} / d$ where $r_{\mathrm{o}}$ is the center-to-center distance between the particles. The interaction of these particles of equal strength $m$ is given by

$$
\begin{aligned}
& E_{12}=\frac{|m|^{2}\left(1-3 \cos ^{2} \theta\right)}{4 \pi \mu_{1} \mu_{0}|r|^{3}} \\
& E_{12}=\frac{|m|^{2}\left(1-3 \frac{r_{0}^{2}}{r_{0}^{2}+x^{2}}\right)}{4 \pi \mu_{1} \mu_{0}\left(r_{0}^{2}+x^{2}\right)^{\frac{3}{2}}}
\end{aligned}
$$

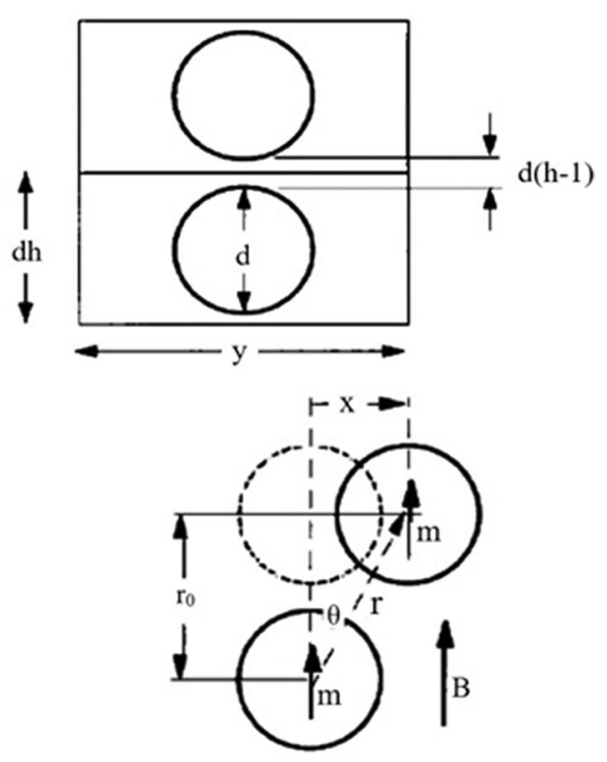

Fig. 1 Relation between rheology and particle polarization 
Scalar shear strain is taken as $x / r$, and the total energy density is taken as this multiplied by the total number of particles divided by the volume. The total energy density is obtained as

$U=\frac{3 \emptyset\left(\varepsilon^{2}-2\right)|m|^{2}}{2 \pi^{2} \mu_{1} \mu_{0} d^{3} r_{0}^{3}\left(1+\varepsilon^{2}\right)^{5 / 2}}$

The shear stress can be obtained by differentiating this energy with respect to strain and taking the average polarization density as the dipole magnetic particle volume per unit volume of particle stress, obtained as

$\sigma=\frac{\emptyset \varepsilon\left(4-\varepsilon^{2}\right) J_{p}^{2}}{8 \mu_{1} \mu_{0} h^{3}\left(1+\varepsilon^{2}\right)^{7 / 2}}$

Maximum shear stress, i.e., yield stress, will be obtained for the maximum value of strain, so differentiating stress with respect to strain and equating to zero yield stress are obtained as

$\sigma_{y}=\frac{0.1143 \emptyset J_{p}^{2}}{\mu_{1} \mu_{0} h^{3}}$

Assuming that saturation takes place uniformly and along the direction of the applied field, the relations including field strength, intrinsic induction, magnetic flux and saturation polarization density are obtained as

$\emptyset_{p}=B_{s} A_{s}=\frac{1}{1+\frac{R_{p}}{R_{m}}} B A$

$\frac{R_{p}}{R_{m}}=k \frac{\frac{2}{3} \emptyset-1}{(1+\alpha)}$

$\mu_{0} H=\frac{B-\emptyset\left(1-\alpha^{3}\right) J_{s}}{1+\frac{3}{2} \emptyset \alpha^{3}}$

$J_{p}=J_{p}=\frac{\frac{3}{2} \alpha^{3} B+\left(1-\alpha^{3}\right) J_{s}}{1+\frac{3}{2} \emptyset \alpha^{3}}$

Equations 6-9 need to be simultaneously solved to obtain the solution for shear stress. This was done using $\mathrm{C}++$ coding.

A Gauss-Jacobi algorithm was employed where we assumed the value for a variable, solved the remaining variables in terms of this variable and verified the governing equation for a maximum error of $2 \%$. If not within

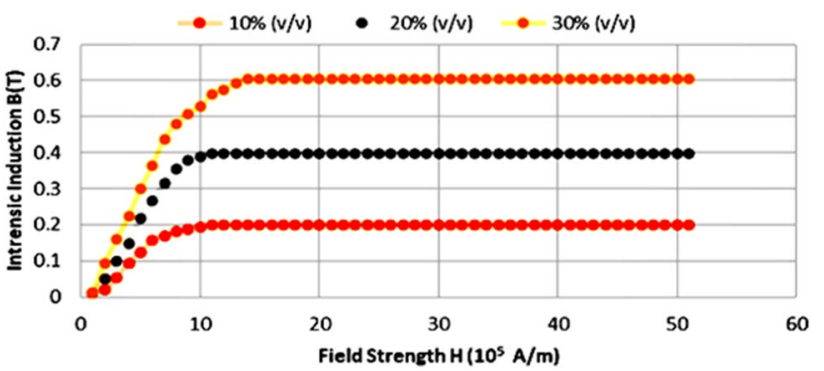

Fig. 2 Relation between intrinsic induction versus field strength

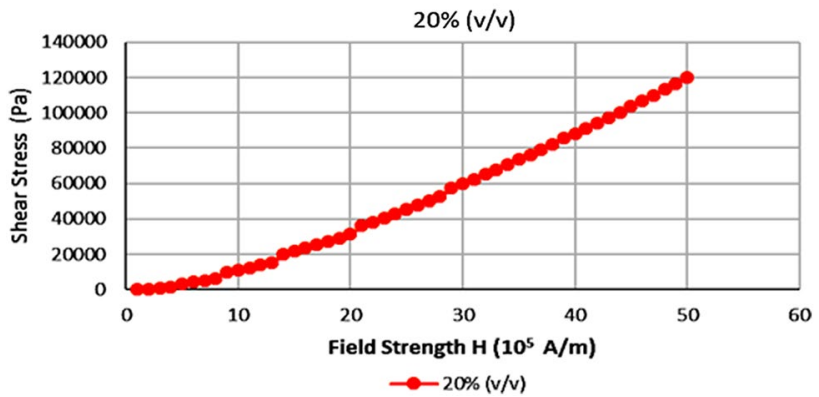

Fig. 3 Relation between field strength and shear stress

this limit, the variable value was changed and the process repeated until it was solved. This was an iteration method. Figure 2 shows the relationship between intrinsic inductions versus field strength.

The variations of induction values with field strength for three volume ratios are given in Fig. 2. As evident from the graph, the higher the volume ratio is, the higher the induction in the fluid. This is because the presence of more particles increases the magnetic effect and thus the induction.

Figure 3 shows the relationship between field strength and shear stress. It was observed that induction increased initially and then reached a saturation value, as expected, when the iron particles became saturated. For increasing volume ratios, the saturation induction increased, and so the yield stress increased with concentration.

Hence, it is seen that the effect of the volume ratio theoretically plays a critical role in intrinsic induction. Verification of the experimental behavior study is carried out with different compositions.

\section{Synthesis of MR fluids}

The major constituents of MR fluids are the carrier fluid, magnetizable particles and additives. The carrier fluid is the major constituent of MR fluid at $50-80 \%$ by volume fraction. Commonly used carrier liquids are mineral, 
synthetic and silicone oils. The size of magnetic particles is on the order of 1-10 $\mu \mathrm{m}$. The sedimentation increases with an increase in the size of magnetic particles. The stabilizers and surfactants help keep the magnetic particles suspended in the carrier fluid.

Shah et al. [37] reported that large particles provide 15 times higher yield stress than small-sized particles. Furthermore, it has been reported that on mixing smaller and larger particles with different weight fractions, the Bingham yield stress value increases by a factor of three compared with large-sized particles dispersed in fluid [38, 39]. The finding implies the mechanical properties of $M R$ fluids are the function of temperature; the steps involved in bringing down the off-state viscosity and shear stress at elevated temperatures were studied, as was the performance degradation for a low-high-low temperature cycle [40]. To synthesize MR fluid, the following steps were followed:

(1) Carbonyl iron $(\mathrm{Cl})$ particles were mixed with lithium grease for $30 \mathrm{~min}$ using a stirrer at $600 \mathrm{rpm}$.

(2) Next, Triton $X$ was added and stirred for another $30 \mathrm{~min}$ at $600 \mathrm{rpm}$.

(3) The base fluid silicone oil was added to the mixture in parts with continues stirring for $3 \mathrm{~h}$ at $600 \mathrm{rpm}$.

By adopting this synthesis method, the dispersion of the magnetic particles in the carrier fluid was better as the particles were coated with grease, which helped in particle suspension $[4,41-43]$.

\subsection{Carrier fluid}

Carrier fluid is the major constituent of MR fluid (50-80\% by weight). The commonly used carrier liquids are mineral, synthetic and silicone oil [44, 45]. With its properties such as low viscosity, temperature stability, compatibility with other materials of the device and rheologic properties, silicone oil with viscosity of $210 \mathrm{cp}$ and density of $0.99 \mathrm{~g} / \mathrm{ml}$ was used as a carrier fluid for the synthesis.

\subsection{Magnetic particles}

The size of magnetic particles is on the order of $1 \mu \mathrm{m}-10 \mu \mathrm{m}$. The sedimentation increases with an increase in the size of magnetic particles [46-50]. Carbonyl iron powders of 2-10 micron size were used in our experiments. Carbonyl iron powder (EC10TR, electrolytic reduced powder, Industrial Metal Powders, Pune, India) was present as suspended particles in the system. The average particle size distribution and apparent density were $14.47 \mu \mathrm{m}$ and
$1.1 \mathrm{~g} / \mathrm{cm}^{3}$, respectively, and the iron content of the powder was $99.56 \%$.

\subsection{Additives}

Additives can be broadly classified as stabilizers and surfactants. Considering the properties such as good adhesion, particularly to metal, non-corrosiveness, heavy load application and good temperature tolerance, lithium grease was selected as a stabilizer, which helped keep the particles suspended in the base fluid by providing a coating, whereas Triton X-100, with $240 \mathrm{cp}$ viscosity, $1.061 \mathrm{~g} / \mathrm{ml}$ and a flash point of $251^{\circ} \mathrm{C}$, served as a surfactant, which helped reduce agglomeration and cluster formation [17, 18, 51-54]. Three different samples were prepared with various combinations of silicone oil, $\mathrm{Cl}$ powder, lithium grease and Triton X. Table 1 gives the detailed composition of MR fluid.

\section{Design of the brake system}

\subsection{Design of the magnetic coil}

The magnetic coil is responsible for the generation of the magnetic field in the system. The magnetic field must be properly controlled so that it is not so high that the saturation level is overcame, but not so low that sufficient magnetic field intensity is not produced [39, 55-58]. A solenoid setup is used to generate the required magnetic field. The important parameters considered for the design are the number of turns of the coil, length of the solenoid, maximum current flowing through the coil and wire specification.

(1) Length of the solenoid ( $L$ ): to reduce the size of the system, the length of the solenoid was considered the same as the width of the coil ring, $2 \mathrm{~cm}$.

(2) Maximum current ( () : considering the safety and battery power availability in the present automotive system, the maximum current value was set as $2 \mathrm{~A}$.

(3) No of turns of the coil $(N)$ : For the synthesized MR fluid, the saturation magnetic field intensity was found to be $25,000 \mathrm{~A} / \mathrm{m}$. The design was carried out

Table 1 Composition of MR fluid

\begin{tabular}{lccl}
\hline Constituents & Sample 1 $(\mathrm{g})$ & Sample 2 $(\mathrm{g})$ & Sample 3 $(\mathrm{g})$ \\
\hline Silicone oil & 18.53 & 17.76 & 19.207 \\
Cl powder & 6.412 & 9.632 & 17.12 \\
Lithium grease & 2.492 & 3.936 & 6.072 \\
Triton X-100 & 0.504 & 0.672 & 0.594 \\
\hline
\end{tabular}


considering that the maximum current $(2 \mathrm{~A})$ saturation of the fluid took place and maximum shear stress was obtained.

The magnetic field intensity for a solenoid is given by

$H=N I / L$

From this the number of turns of the coil was obtained as 250 .

Wire specification: Copper winding wires are classified from gauge 1 to 30 based on their diameter. Each gauge has different current density values. The best result was obtained by employing the wire with maximum current density. Therefore, AWG 21 was selected for the coil with a maximum current density value of $2.653 \mathrm{~A} / \mathrm{mm}^{2}$.

Thus, the design of the coil was carried out and the important parameters set.

\subsection{Magnetic circuit analysis using COMSOL}

The magnetic field strength is a critical aspect in the MR braking system. To predict the strength and distribution of the magnetic field at a given point around the rotating disc by the magnetic circuit, a circuit was designed and its magnetic strength analyzed using COMSOL software, which helped to find the intensity at intermediate points and regions of maximum intensity. The analysis was used to determine the length of the core to be used in the system. For modeling of the MR brake, the magnetic field module was employed as analysis of the magnetic field was involved. As the system is cylindrical in shape and there is no change in magnetic field along the circumferential direction, the problem could be treated as a 2D axisymmetric problem. Since we used a 250-turn coil, a multi-turn coil domain is used for the current input.

\subsubsection{Core length of the brake system}

Initially, the study was conducted to compare a 70-mm and 30-mm core by applying the same current and number of turns of the coil, and the generated magnetic field intensity was analyzed. The plot comparing the values is shown in Fig. 4a, b for $70 \mathrm{~mm}$ and $30 \mathrm{~mm}$, respectively.

Figure $4 a, b$ shows the magnetic field intensity is not highly dependent on the core length. The area and strength of field intensity were almost similar in both the 70-mm- and 30-mm-long cores. Therefore, it was not advantageous to increase the core length further. Thus, the core length was selected as $30 \mathrm{~mm}$. The core length is the difference between the outer and inner radii of the rotor disc.


Fig. 4 a Magnetic field intensity distribution for the 70-mm core. $\mathbf{b}$ Magnetic field intensity distribution for the $30-\mathrm{mm}$ core

\subsubsection{Calculation of the rotor diameter}

The design was based on the $20-\mathrm{cm}$ outer diameter of the casing. The output torque was taken as $30 \mathrm{~N}-\mathrm{m}$. Braking torque is given by

$T_{b}=2 \pi N \int_{r_{w}}^{r_{z}}\left(\mu_{p} \frac{r \omega}{h}+k H^{\beta}\right) r^{2} \mathrm{~d} r$

Equation (11) includes both viscous torque and torque due to the magnetic field. Solving with both these variables is difficult, so we neglected the viscous torque for our derivation. The braking torque equation becames

$T=2 \pi N \int_{r_{i}}^{r_{o}} K H^{\beta} r^{2} \mathrm{~d} r$

The shear stress was $K H^{\beta}$, and this was obtained from the standard graph for the MR fluid. The values were obtained as $K=0.2$ and $\beta=1.066$.

Magnetic field intensity $(H)$ corresponding to maximum current was used $(25,000 \mathrm{~A} / \mathrm{m})$. Integrating Eq. (12) and substituting (ro-ri) as $30 \mathrm{~mm}$, we obtained radii as outer radius $=39 \mathrm{~mm}$ and inner radius $=69 \mathrm{~mm}$. 


\subsubsection{Magnetic field analysis}

The dimensions of the rotor were used to further analyze the system with the magnetic field applied. A fluid gap of $1 \mathrm{~mm}$ was used for the purpose of the analysis. Figure 5 shows the magnetic field intensity distribution. It is evident that the whole of the field intensity is concentrated at the fluid gap.

\subsubsection{Design of the rotor shaft}

The shaft was designed taking the output torque as $30 \mathrm{Nm}$. Taking a safety factor of 2, the load coming on the shaft was $60 \mathrm{Nm}$. The AISI 304 material was selected, which has a tensile strength of $206 \mathrm{MPa}$. Taking a permissible shear stress as $30 \%$ of tensile strength, the permissible shear strength was $61.8 \mathrm{MPa}$. Using the ASME code, a shaft diameter of $10 \mathrm{~mm}$ was obtained.

\subsubsection{Design of the rotor}

The thickness is set at $5 \mathrm{~mm}$ to reduce the total size of the system. AISI 1018 is selected as the material for the rotor as it should be magnetic for maximum flux linkage in the magnetic circuit. This increases the relative permeability of the circuit and thus increases the magnetic field induction $[39,59,60]$. The high-speed rotor operation simulates disturbance for the flow field in the internal coolent leading to vortex formation; hence, this phenomenon can be considered for the heat dissipation [61]. The stress analysis of the rotor is done in SOLIDWORKS and shown in Fig. 6. The safety factor obtained is 30 , which is acceptable.

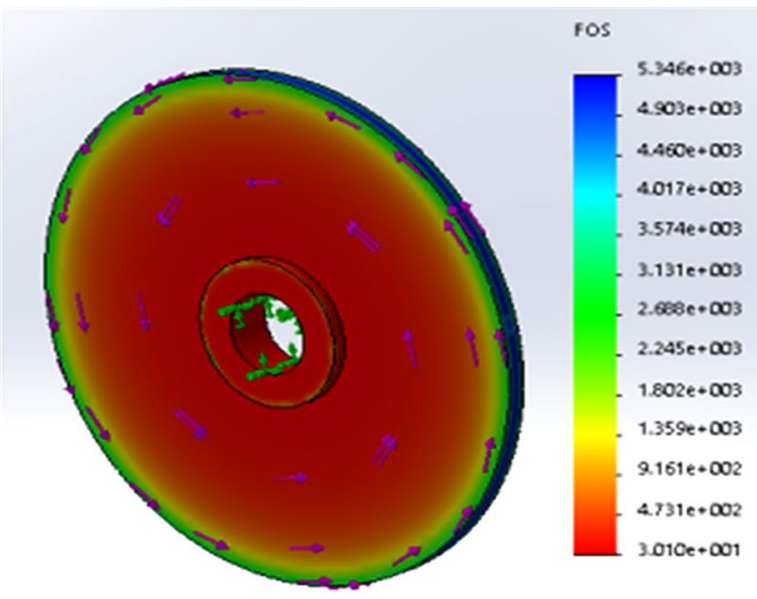

Fig. 6 Stress analysis of the rotor disc

\subsubsection{Design of the coil ring}

The coil is wound on the coil ring. The dimensions of the ring are set according to the outer diameters of the rotor and casing. The outer diameter is $138 \mathrm{~mm}$. Taking a 1-mm gap for fluid around the rotor, the inner diameter of the coil ring is set at $140 \mathrm{~mm}$. The outer diameter is set as $168 \mathrm{~mm}$ so that the casing can be $3 \mathrm{~cm}$ thick, and $1 \mathrm{~mm}$ clearance is given around the coil for the winding. The material selected is AISI 304 (SS 304). Stainless steel is required as the ring needs to be nonmagnetic; otherwise, it will reduce the effective field intensity available at the fluid gap. The dimensions are inner diameter $=140 \mathrm{~mm}$; outer diameter $=168 \mathrm{~mm}$; ring
Fig. 5 Magnetic field intensity distribution

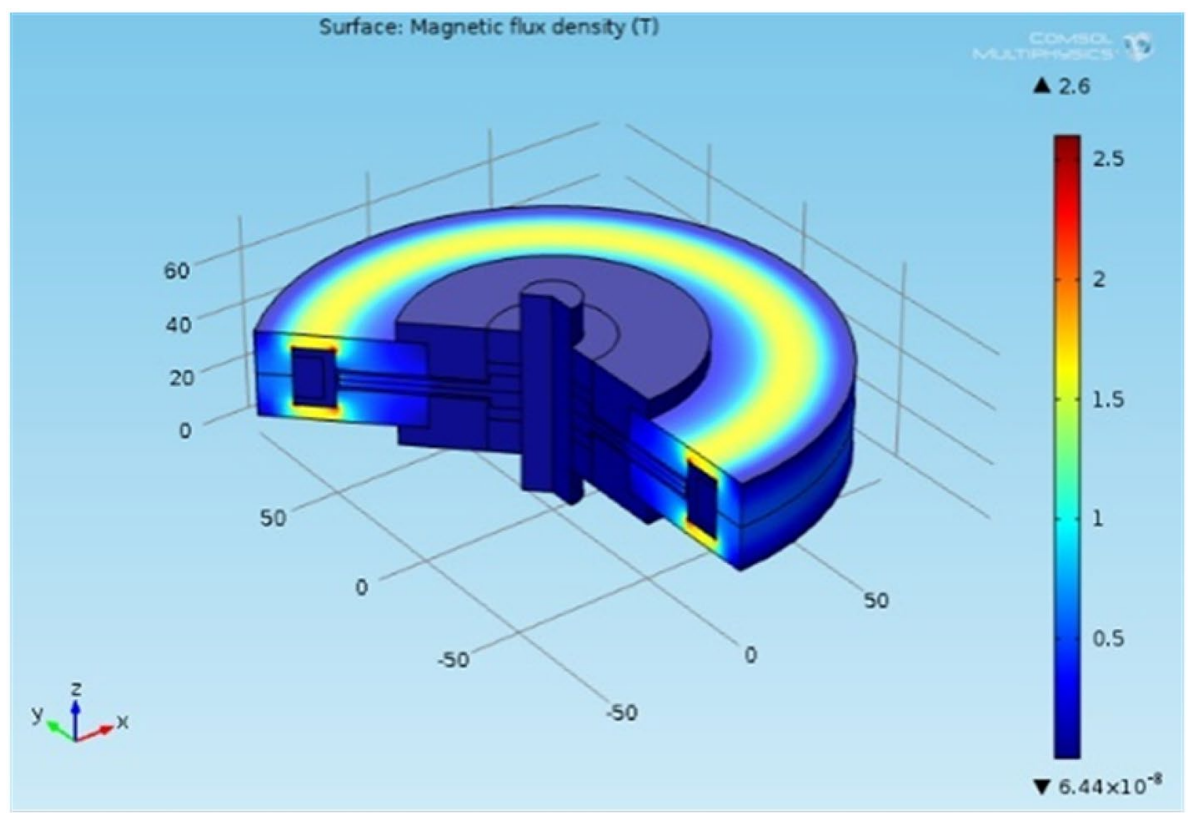

SN Applied Sciences A SPRINGER NATURE journa 
width $=15 \mathrm{~mm}$; ring thickness $=4 \mathrm{~mm}$; material is AISI 304 (SS 304).

\subsubsection{Design of the bearing and sealing}

There is no axial load for the system; only a radial load is present. Therefore, we use a single-row deep groove bearing. For the bearing, the maximum rotational speed is $1250 \mathrm{rpm}$. Assuming an expected life of $10,000 \mathrm{~h}$, the design is done. Therefore, the bearing selected is 6004 RR. The dimensions are: inner diameter $=20 \mathrm{~mm}$; outer diameter $=42 \mathrm{~mm}$; bearing width $=12 \mathrm{~mm}$. A PTFE gasket is used at the casing joint for proper working.

Oil is present between the components, and its leakage must be avoided. If leakage is present, the amount will decrease, and thus the torque generated will decrease and proper braking will not occur. Therefore, oil seals are provided at the bearing interfaces.

\subsubsection{Design of the casing}

The casing material should be non-magnetic because the magnetic flux would link across the casing and leak outside if the casing is magnetic. This would result in a decrease in the effective flux linkage available at the fluid gap and thus reduce the braking torque developed [62]. The finding of various wedge angles implies substantial auto energizing occurs for smaller wedge angles; hence, an actuator with smaller volume has a magnified brake torque [63]. Also, if it were magnetic, effects of outside magnet fields would interfere with the proper working of the brake system. Therefore, the material selected is aluminum 6061.

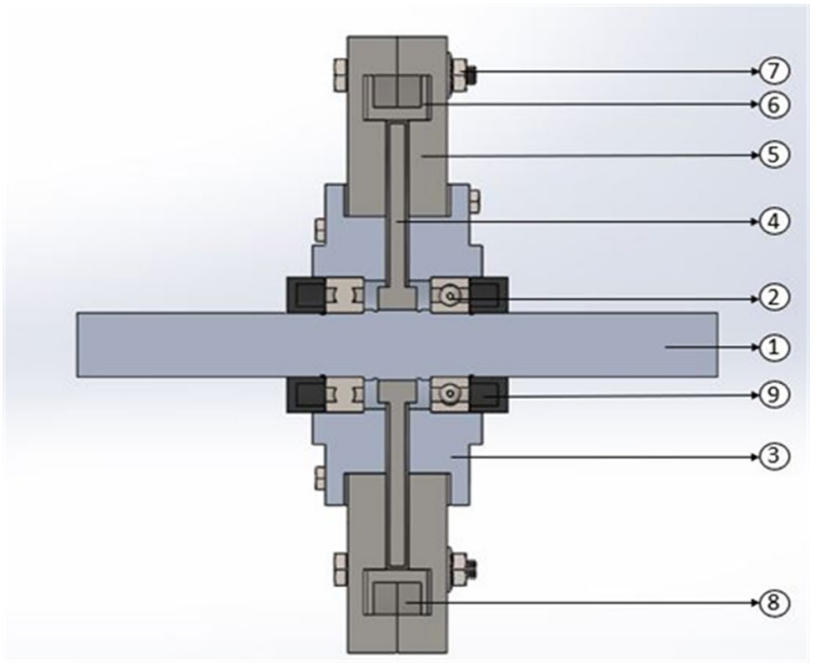

Fig. 7 Complete brake design
The complete model of the brake system along with the components is shown in Fig. 7. Description of the parts is given in Table 2.

\section{Test setup}

\subsection{Test layout}

The braking torque developed by the brake system needs to be measured. The basic working of the test setup is to impart torque to a flywheel from an engine. When the flywheel has reached sufficient speed, the engine is disengaged using a clutch, and the brake is applied. The time required for the flywheel to stop is noted, and from this the braking torque developed is calculated. Figure 8 gives the brake setup at NIT Calicut.

A 300-CC, 10-HP Briggs \& Straton engine is used to impart the torque. The engine has a maximum speed of $3800 \mathrm{rpm}$ and maximum torque of 19.6. It is a petrol engine and started by cranking. The output shaft is coupled with the clutch gear and imparts the motion to the rotor shaft. The clutch is in the disengaged position when starting the engine. A multi-plate wet clutch (BAJAJ CT100) with an actuator is used.

Table 2 Materials used

\begin{tabular}{lll}
\hline No. & Part & Material \\
\hline 1 & Shaft & AISI304 \\
2 & Bearing & SKF6004 \\
3 & Casing & Al6061 \\
4 & Brake rotor & AISI 1018 \\
5 & Magnetic casing & AISI 1018 \\
6 & Coil ring & AISI 1018 \\
7 & Bolt & Bought out \\
8 & Magnetic coil & Copper \\
9 & Oil seal & Natural rubber \\
\hline
\end{tabular}

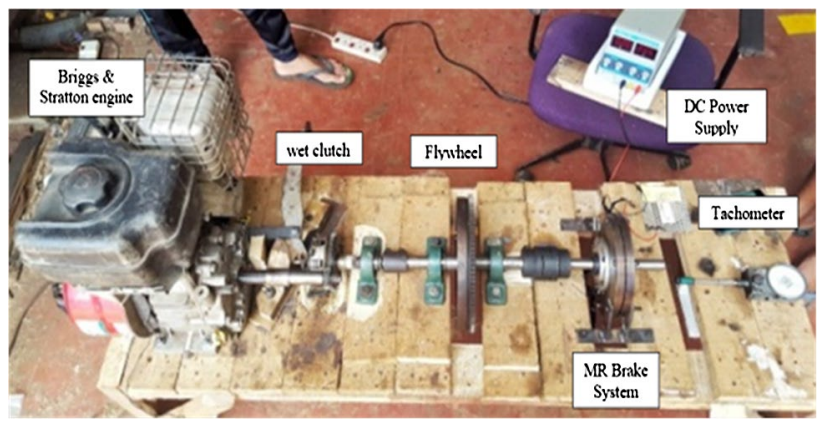

Fig. 8 Brake setup at NIT Calicut 
The purpose of the clutch is to impart torque from the engine when needed and disengage when applying the brake. The flywheel is taken from a Maruti car and weighs $12 \mathrm{~kg}$.

\subsection{Testing the brake system}

The testing the brake system is done using the test setup explained in Sect. 5.1. The primary aim is to find the braking torque developed from the system. Even when the magnetic field is not applied, due to the inherent viscosity a friction torque will be developed that resists the rotation of the shaft. We must find this torque first, and only then can we apply a magnetic field to find the actual braking torque developed. To find the viscous torque, the rotor shaft is rotated at a specific speed, the engine is disengaged, and time required for the rotor to stop is recorded.

The braking effect should only happen when the clutch is disengaged. To facilitate this, the switch assembly for the current supply to the magnetic coils is designed in such a way that the coils are energized on the disengagement of clutch so that a magnetic field is developed in the system. The testing procedure for the same is explained below.

1. Disengage the clutch from the rotor shaft so that when the engine is started there is no load on the engine.

2. Start the engine by cranking. Make sure fuel is on.

3. After the engine starts to run smoothly, slowly engage the clutch, and torque is transmitted to the rotor shaft.

4. Slowly increase the fuel intake and thus the power of the engine, which will lead to a speed increase of the rotation of the crankshaft and thus the rotor shaft.

5. Continuously measure the rotational speed of the shaft using a tachometer, and as the speed reaches $900 \mathrm{rpm}$, keep the accelerator position constant and allow the speed to stabilize.

6. When the speed is staying constant, disengage the clutch, the engine is disconnected, and the speed of the shaft drops and finally reaches 0 .

7. The time taken for the shaft to stop is taken. This is the time from the moment clutch is disengaged until the shaft stops.

From this, the viscous torque can be calculated as follows.

The moment of inertia of the flywheel is $I$, the rotational speed $=\omega \mathrm{rad} / \mathrm{s}$, the time required for stopping is $t$, and then the viscous torque develops, $T=l a=l \omega / t$. Next, to find the braking torque developed, the same procedure is followed up to making the rotational speed constant at $900 \mathrm{rpm}$. The instant the clutch is disengaged leads to current flow through the magnetic coil, thus creating a magnetic field and braking of the rotor. In a similar fashion, the time taken for the flywheel to stop and the same calculation give the braking torque developed by the system. The maximum current limit is $2 \mathrm{~A}$, and to get the variation of braking torque with the current applied, the various current input values vary from 0 to $2 \mathrm{~A}$. The current input values are $0,0.2,0.4$, etc. The corresponding stopping times for these current values are noted, and the braking torque is calculated for different current values. To facilitate measuring the time required for braking, a slow-motion camera is employed, and the time taken is used in the calculations.

\section{Results and discussion}

\subsection{Viscous torque developed}

Viscous torque is obtained by measuring the time taken for the flywheel to stop rotating without the application of current, which causes generation of a magnetic field. We set the test speed at $900 \mathrm{rpm}$. The time taken for the flywheel speed to drop from $900 \mathrm{rpm}$ to 0 is noted:

Moment of inertia of flywheel, $I=0.18432 \mathrm{~kg} \mathrm{~m}^{2}$.

Rotational speed, $\omega=94.24 \mathrm{rad} / \mathrm{s}$.

Time taken for the flywheel to stop, $t=4.73 \mathrm{~s}$.

Viscous torque developed, $T=1 \omega / t=3.67 \mathrm{Nm}$.

This torque value is very low and will not cause many problems during normal working of the rotor shaft; this torque will be present even when the brake is not applied.

\subsection{Braking torque developed}

The test is conducted by varying the current from 0 to $2 \mathrm{~A}$ and finding the time taken for the flywheel to stop and then finding the braking torque developed.

The test is conducted for three MR fluids. Figure 9 shows the variation of braking torque for various current values $(0-2 A)$. Figure 9 shows the initial variation

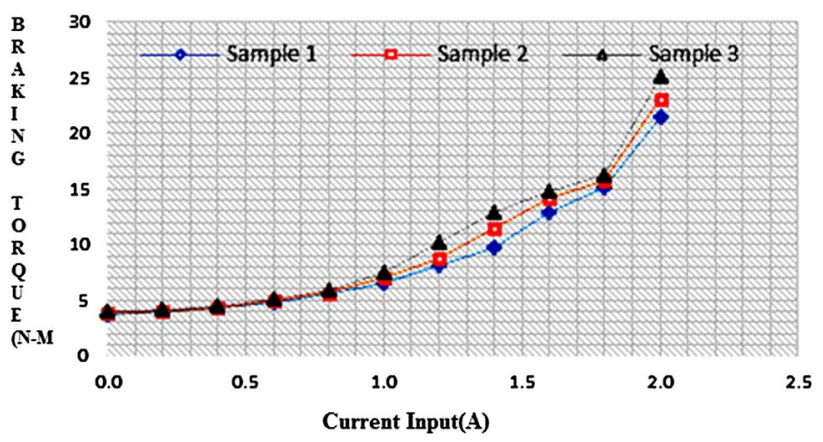

Fig. 9 Braking torque versus current 


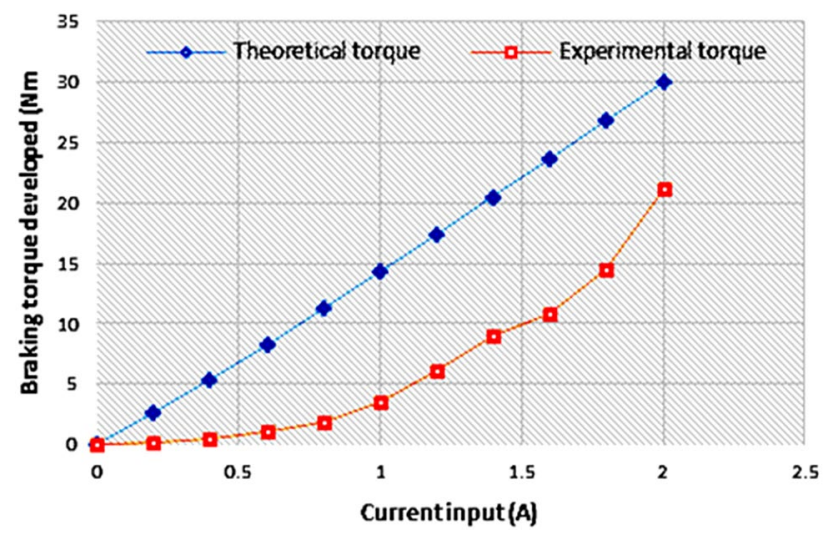

Fig. 10 Experimental torque versus theoretical torque

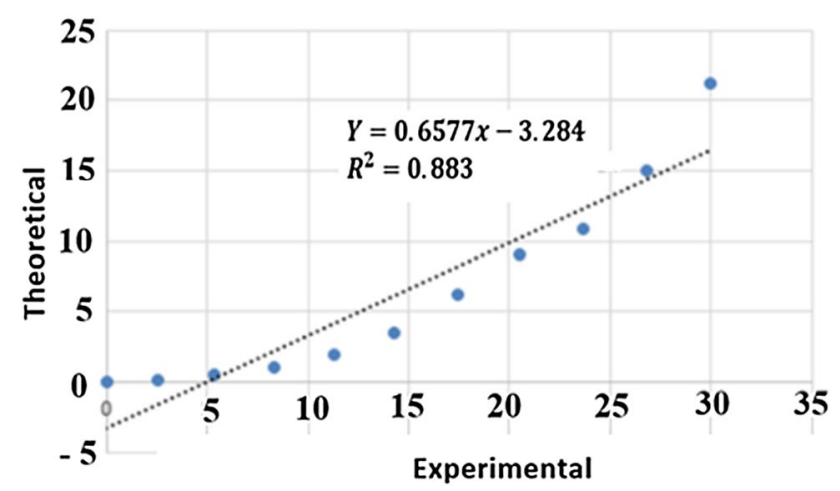

Fig. 11 R square plot for theoretical and experimental results

of braking torque with current is similar for all samples. This is because saturation has not occurred among them, and the properties are almost similar. As the current is increased, the sample with higher particle composition shows the greatest increase in braking torque developed. Sample 3 is the ideal choice for MR fluid for the brake system as it develops the highest torque. However, checking with the sedimentation and viscosity values, we find that sedimentation is high for sample 3 , and the viscous torque developed is a little higher. From these values, we took sample 1 as the best choice for the system; it has a braking torque of $21.435 \mathrm{Nm}$. Figure 10 shows the comparison of the experimental and theoretical torque. The values obtained experimentally show a deviation from the theoretical value because of the different conditions. The major reason may be the coating of lithium grease over the dispersed particles, which contributes to lowering the magnetic strength of the fluid and also the sedimentation of particles over a period of time resulting in fewer particles participating in the phase transformation and application of torque. Figure 11 depicts the $\mathrm{R}$ square plot of theoretical results vs. the experimental results. The $\mathrm{R}$ square value equal to 0.88 indicates the zero discrepancy between the observed and predicted values; hence, the results are quite acceptable and fit the model well.

\section{Conclusions}

The MR fluid was synthesized using iron carbonyl particles, silicone oil, lithium grease and Triton X-100 as constituents. Three samples were prepared by changing the concentrations of the particles in the fluid, and the optimum concentration against sedimentation was obtained. Two sizes of particles were tested. Mathematical modeling of the fluid was done using $\mathrm{C}++$ coding, and the mathematical model was analyzed by relating the particle size, yield strength and magnetic strength. The characteristics were analyzed. The brake was designed taking $30 \mathrm{Nm}$ as the required braking torque. A test setup was manufactured, including the engine, clutch and flywheel. The test was conducted on the brake system by changing the input current from 0 to $2 \mathrm{~A}$ and finding the torque values. Sample 1 was the best choice and was also selected as the optimum composition from the sedimentation and viscosity test values. The other sample might have had the maximum torque output, but also had high viscous torque and caused very high resistance against the normal operation of the rotor.

The maximum torque developed was $22 \mathrm{Nm}$, and our design used $30 \mathrm{Nm}$. The experimentally obtained value was less than the theoretical value. Many factors could have caused this deviation. The first is that knowing the time taken for braking is difficult and prone to deviate from the actual time. To avoid errors, we took multiple readings for the current value. Second, there is inherent friction in the system, which was not included in the analysis. The braking torque of $22 \mathrm{Nm}$ was achieved from a single-disc rotor MR brake. By employing a multi-rotor plate brake, the torque increased proportionally, and this made the brake sufficient for the current automobile application. Thus, the MR brake is most efficient for use for current automobiles because of its various advantages as previously detailed.

In general, the experimental results showed that the designed braking system with in-house developed MR fluid attained the required braking torque with less current input and quick response to actuation. In addition to this, the effect of surface tempering and surface roughness 
can be studied to achieve higher braking torque; also, the particle size plays an important role in determining the yield strength and could be a factor of interest for future development.

\section{Compliance with ethical standards}

Conflict of interest The authors declare that they have no conflict of interest.

\section{References}

1. Stanway R, Sproston J, El-Wahed A (1996) Applications of electro-rheological fluids in vibration control: a survey. J Smart Mater Struct 5(4):464-482

2. Wang J, Meng G (2001) Magnetorheological fluid devices: principles, characteristics and applications in mechanical engineering. J Mater Design Appl 215(3):165-174

3. Ahn Y, Ahmadian M, Morishita S (2010) On the design and development of a magneto-rheological mount. J Veh Syst Dyn 32(2-3):199-216

4. Wang $X$, Gordaninejad F (2006) Study of magnetorheological fluids at high shear rates. Rheol Acta 45(6):899-908

5. Katiyar A, Singh AN, Shukla P, Nandi T (2012) Rheological behavior of magnetic nanofluids containing spherical nanoparticles of Fe-Ni. Powder Tech 224:86-89

6. Xu Y, Qu W, Ko J (2000) Seismic response control of frame structures using magnetorheological/electrorheological dampers. J Earthq Eng Struct Dyn 29(5):557-575

7. Liu W (2005) Ph.D. Thesis. Department of Mechanical Engineering Worcester Polytechnic Institute

8. Yoshida K, Soga T, Kawachi M, Edamura K, Yokota S (2010) Magneto-rheological valve-integrated cylinder and its application. J Syst Cont Eng 224(1):31-40

9. Yoo J, Wereley N (2002) Design of a high-efficiency magnetorheological valve. J Intell Mater Syst Struct 13(10):679-685

10. Kumbhar B, Patil S, Sawant S (2015) Synthesis and characterization of magneto-rheological (MR) fluids for MR brake application. Int J Eng Sci Technol 18(3):432-438

11. Sarkar C, Hirani H (2015) Development of a magnetorheological brake with a slotted disc. J Automob Eng 229(14):1907-1924

12. Sarkar C, Hirani H (2013) Theoretical and experimental studies on a magnetorheological brake operating under compression plus shear mode. Smart Mater Struct 22(11):115032

13. Sukhwani VK, Hirani H (2008) Design, development, and performance evaluation of high-speed magnetorheological brakes. Proc Inst Mech Eng L: J Mater Des Appl 222(1):73-82

14. Ubaidillah, Permata ANS, Mazlan SA, Tjahjana DP, Widodo PJ (2017) Magnetostatic simulation on a novel design of axially multi-coiled magnetorheological brakes. Mater Sci Eng 257:012052

15. Attia E, Elsodany $\mathrm{N}$ et al (2017) Theoretical and experimental study of magneto-rheological fluid disc brake. J Alex 56(2):189-200

16. Park EJ, Stoikov D, da Luz LF, Suleman A (2006) A performance evaluation of an automotive magnetorheological brake design with a sliding mode controller. Mechatronics 16(7):405-416

17. Karakoc K, Park EJ, Suleman A (2008) Design considerations for an automotive magnetorheological brake. Mechatronics 18(8):434-447
18. Li WH, Du H (2003) Design and experimental evaluation of a magnetorheological brake. Int J Adv Manuf Technol 21(7):508-515

19. Park EJ, da Luz LF, Suleman A (2008) Multidisciplinary design optimization of an automotive magnetorheological brake design. Comput Struct 86(3):207-216

20. Nguyen QH, Choi SB (2010) Optimal design of an automotive magnetorheological brake considering geometric dimensions and zero-field friction heat. Smart Mater Struct 19(11):115024

21. Nguyen PB, Choi SB (2012) A new approach to magnetic circuit analysis and its application to the optimal design of a bi-directional magnetorheological brake. Smart Mater Struct 20(12):125003

22. Nguyen QH, Choi SB (2012) Optimal design of a novel hybrid MR brake for motorcycles considering axial and radial magnetic flux. Smart Mater Struct 21(5):055003

23. Assadsangabi B, Daneshmand F, Vahdati N, Eghtesad M, Bazargan-Lari Y (2011) Optimization and design of disk-type MR brakes. Int J Automot Technol 12(6):921-932

24. Younis A, Karakoc K, Dong Z, Park EJ, Suleman A (2011) Application of SEUMRE global optimization algorithm in automotive magnetorheological brake design. Struct Multidiscip Optim 44(6):761-772

25. Marannano GV, Virzì MG, Duboka Č (2011) Preliminary design of a magnetorheological brake for automotive use. In: Science and motor vehicles, international automotive conference, pp 19-21

26. Sarkar C, Hirani H (2015) Design of magnetorheological brake using parabolic shaped rotating disc. Int J Curr Eng Technol 5(1):719-724

27. Patil SR, Powar KP, Sawant SM (2016) Thermal analysis of magnetorheological brake for automotive application. Appl Therm Eng 98(1):238-245

28. Patil SR, Sawant SM (2014) Reliability analysis of automotive magnetorheological brake: a qualitative approach. In: ASME 2014 12th biennial conference on engineering systems design and analysis, July

29. Abdullah MA, Zainordin AZ, Hudha K (2015) Performance evaluation of shaft speed control using a magnetorheological brake. Int J Automot Mech Eng 11:2654

30. Poznic A, Casniji F (2002) Analysis of a cylindrical magnetorheological fluid brake. J Mater Process Technol Automot 21(2):68-78

31. Kumbhar S, Patil A, Baskar P (2016) Simulation of magnetorheological brake for automotive application. Int J Eng Res 5(6):462-466

32. Kavlicoglu B, Gordaninejad F, Evrensel CA, Fuchs F, Korol G (2003) A multi-plate magneto-rheological fluid limited slip differential clutch, vol 5054, pp 341-349

33. Tan K, Stanway R, Bullough W (2007) Braking responses of inertia/load by using an electro-rheological (ER) brake. Mechatronics 17:277

34. Benetti M, Dragoni E (2006) Nonlinear magnetic analysis of multi-plate magnetorheological brakes and clutches. In: COMSOL UsersConference Milan

35. Poznic A, Zelic A, Szabo L (2012) Magnetorheological fluid brake - basic performances testing with magnetic field efficiency improvement proposal. Hung J Ind Chem Veszpr 40(2):113-119

36. Bier R, Huey $\mathrm{H}$, Associates V, Alto $\mathrm{P}$ (1984) Design considerations for magnetorheological brakes. Computer (Long Beach Calif) 19(5):834-837

37. Shah K, Upadhaya R, Aswal V (2012) Influence of large size magnetic particles on the magneto-viscous properties of ferrofluid. J Smart Mater Struct 21(7):750 
38. Kamble VG, Kolekar S (2014) Analysis of rheological properties of MR fluid based on variation in concentration of iron particles. Am J Nanotechnol 5(2):12

39. Kamble VG, Kolekar S, Madivalar C (2015) Preparation of magnetorheological fluids using different carriers and detailed study on their properties. Am J Nanotechnol 6:7

40. Wang D, Zi B, Zeng Y, Xie F, Hou Y (2017) Measurement of temperature-dependent mechanical properties of magnetorheological fluids using a parallel disk shear stress testing device. J Mech Eng Sci 231(9):1725-1737

41. Tanner RI (2009) The changing face of rheology. J Non-Newtonian Fluid Mech 157:141-144

42. Ashtiani M, Hashemabadi SH, Ghaffari A (2015) A review on the magnetorheological fluid preparation and stabilization. J Magn Magn Mater 374:711-715

43. Jolly MR, Bender JW, Carlson JD (2001) Properties and applications of commercial magnetorheological fluids. Thomas Lord Research Centre, Lord Corporation, Cary, NC

44. Kolekar S, Kurahatti RV, Kamble VG, Choi S-B (2014) Synthesis and characterization of innovative type magneto-rheological fluid. Int J Nanosci 13:1450009

45. Kolekar S, Kurahatti RV, Kamble VG, Choi S-B (2018) Preparation of magnetorheological fluid and study on its rheological properties. Int J Nanosci 13(2):1450009

46. Wereley NM et al (2006) Bidisperse magnetorheological fluids using Fe particles at nanometer and micron scale. J Intell Mater Syst Struct 17(5):393-401

47. Kim MS, Liu YD, Park BJ, You CY, Choi HJ (2012) Carbonyl iron particles dispersed in a polymer solution and their rheological characteristics under applied magnetic field. J Ind Eng Chem 18(2):664-667

48. Wang D, Zi B, Zeng Y, Hou Y, Meng Q (2014) Temperaturedependent material properties of the components of magnetorheological fluids. J Mater Sci 49(24):8459-8470

49. Kumbhar BK, Patil SR (2014) A study on properties and selection criteria for magneto-rheological (MR) fluid components. Int J Chem Tech Res 6(6):3303-3306

50. Kolekar S, Kurahatti RV, Prashanth PK, Kamble V, Reddy N (2014) Preparation of a Silicon oil based Magneto Rheological Fluid and an Experimental Study of its Rheological Properties using a Plate and Cone Type Rheometer. Inst Smart Struct Syst 3(2):23-26

51. Bica I (2004) Magnetorheological suspension electromagnetic brake. J Magn Magn Mater 270(3):321-326
52. Sarkar C, Hirani H (2013) Synthesis and characterization of antifriction magnetorheological fluids for brake. Defense Sci J 63:408

53. Jain D, Avchare KR (2016) Design, fabrication and testing of low cost magneto-rheological fluid brake testing machine. J Mater Sci 4(2):20-25

54. Huang J, Zhang JQ, Yang Y, Wei YQ (2002) Analysis and design of a cylindrical magnetorheological fluid brake. J Mater Process Technol 129:559-562

55. Vijay K, Hirani H (2008) A comparative study of magnetorheological-fluid-brake and magnetorheological-grease-brake. J Tribol Online 3(1):31-35

56. Aparow VR, Ahmad F, Hudha K, Jamaluddin H (2013) Modelling and PID control of antilock braking system with wheel slip reduction to improve braking performance. Int J Veh Saf 6(3):265-296

57. Dashwant AM (2018) A review on Experimental Evaluation of Magneto-rheological Brake. J Automob Eng Appl 2(2):1-8

58. Sohn JW, Gang HG, Choi S-B (2018) An experimental study on torque characteristics of magnetorheological brake with modified magnetic core shape. Adv Mech Eng 10:1

59. Lijesh KP, Kumar D, Hirani H (2017) Effect of disc hardness on MR brake performance. Eng Fail Anal 74:228-238

60. Jolly MR, Carlson JD, Muñoz BC (1996) A model of the behaviour of magnetorheological materials. Smart Mater Struct 5(5):607-614

61. Zi B, Qian S, Qian J (2017) Steady-state heat-flow coupling field of a high-power magnetorheological fluid clutch utilizing liquid cooling. J Fluid Eng 139:111105

62. Ali S, Suresh A, Seetharamaiah N (2014) Principles, characteristics and applications of magneto rheological fluid damper in flow and shear mode. Procedia Mater Sci 6:1547-1556

63. Yu L (2016) Magnetorheological and wedge mechanism-based brake-by-wire system with self-energizing and self-powered capability by brake energy harvesting. IEEE/ASME Trans Mechaton 21(5):1-13

Publisher's Note Springer Nature remains neutral with regard to jurisdictional claims in published maps and institutional affiliations. 